\title{
Perivascular Adipose Tissue and Its Role in Type 2 Diabetes and Cardiovascular Disease
}

\author{
Rick I. Meijer • Erik H. Serne • Yvo M. Smulders • \\ Victor W. M. van Hinsbergh • John S. Yudkin • \\ Etto C. Eringa
}

Published online: 5 April 2011

(C) The Author(s) 2011. This article is published with open access at Springerlink.com

\begin{abstract}
Obesity is associated with insulin resistance, hypertension, and cardiovascular disease, but the mechanisms underlying these associations are incompletely understood. Microvascular dysfunction may play an important role in the pathogenesis of both insulin resistance and hypertension in obesity. Adipose tissue-derived substances (adipokines) and especially inflammatory products of adipose tissue control insulin sensitivity and vascular function. In the past years, adipose tissue associated with the vasculature, or perivascular adipose tissue (PAT), has been shown to produce a variety of adipokines that contribute to regulation of vascular tone and local inflammation. This review describes our current understanding of the mechanisms linking perivascular adipose tissue to vascular function, inflammation, and insulin resistance. Furthermore, we will discuss mechanisms controlling the quantity and adipokines secretion by PAT.
\end{abstract}

Keywords Obesity · Insulin resistance $\cdot$ Intracellular signaling $\cdot$ Endothelium

\section{Introduction}

Obesity is recognized as one of the major current challenges to health care in Western societies. This is

R. I. Meijer · V. W. M. van Hinsbergh • E. C. Eringa $(\bowtie)$ Department of Physiology, VU University Medical Center, Amsterdam, The Netherlands

e-mail: e.eringa@vumc.nl

R. I. Meijer • E. H. Serne $\cdot$ Y. M. Smulders $\cdot$ J. S. Yudkin Department of Internal Medicine, VU University Medical Center, Amsterdam, The Netherlands due to its high and increasing prevalence and the associated risk of type 2 diabetes and cardiovascular disease. The hallmark of obesity, an increased mass of adipose tissue, has triggered a wave of interest in the physiologic and pathophysiologic functions of adipose tissue. These functions depend on the quantity, location, consistency, and bioactive products of adipose tissue. In this review, we will consider the biology of adipose tissue at a very relevant location for regulation of tissue perfusion and blood pressure, the vasculature. We have previously proposed that signaling from perivascular adipose tissue (PAT) to the vasculature ("vasocrine" signaling) may not only cause vascular disease associated with obesity, but also reduce insulin-induced glucose disposal by reducing muscle perfusion. In recent years, evidence has emerged suggesting that this PAT may hold one of the keys to effective future treatment or prevention of both insulin resistance and cardiovascular disease in obesity. This review aims to summarize and evaluate this evidence.

\section{Location, Origin, and Cellular Composition of PAT}

Throughout the body, most arteries and veins with a diameter greater than $100 \mu \mathrm{m}$ are in contact with/ surrounded by adipocytes. The term "perivascular adipose tissue" refers to adipose tissue around vessels, irrespective of location. Known locations of PAT include the coronaries (epicardial adipose tissue) [1], aorta (periaortic adipose tissue) [2], and the microvascular beds of the mesentery [3], muscle [4], kidney [5], and adipose tissue [6••].

PAT consists of adipocytes, fibroblasts, stem cells [7], mast cells $[8,9]$, and nerves [8]. PAT is initially formed in the embryological phase and remains in place throughout 
life; in times of nutrient abundance and obesity, PAT expands and undergoes an inflammatory transformation. In the first phase, which mainly takes place in utero, PAT is assumed to form from mesoderm in association with the developing blood vessels [10]. We will not further discuss this phase in detail here, as the pathophysiologic growth of PAT associated with vascular dysfunction mainly occurs in adults. The volume of PAT is associated with the quantity of intra-abdominal adipose tissue $[11,12 \bullet \cdot]$.

The mechanisms involved in the expansion of PAT involve differentiation of resident mesenchymal stem cells/ preadipocytes as well as infiltration and differentiation of stem cells from bone marrow. The conversion of stem cells/ preadipocytes to adipocytes can be triggered by activation of peroxisome proliferator-activated receptor- $\gamma$ (PPAR- $\gamma$ ) [13], and can be inhibited by the Wnt signaling pathway and preadipocyte factor 1 (pref-1) [14]. Interestingly, mast cells have recently been shown to control adipose tissue expansion as well as insulin sensitivity [15]. This adipogenic effect of mast cells is likely to be mediated by PPAR- $\gamma$, as mast cells are a known source of the natural PPAR- $\gamma$ activator $15 \mathrm{~d}-\mathrm{PGJ}_{2}[16]$.

Infiltration of PAT by immune cells such as macrophages and $\mathrm{T}$ lymphocytes has been demonstrated in periaortic adipose tissue in obesity and atherosclerosis [2, 17, 18]. The accumulation of $\mathrm{T}$ lymphocytes may trigger further expansion of PAT because T cells, like mast cells, stimulate adipogenesis by production of $15 \mathrm{~d}-\mathrm{PGJ}_{2}$ and activating PPAR- $\gamma$ [17]. Macrophages do not affect the quantity of PAT, but produce cytokines that alter the secretion of adipokines by PAT. Accumulating evidence suggests that the products of PAT (ie, adipokines) contribute to regulation of vascular function. In this regard, both protective physiologic and pathologic properties of PAT have been proposed.

\section{Adipokines}

Adipokines, initially described as adipose tissue-derived cytokines, are now known as a large and diverse group of substances with endocrine or paracrine functions secreted by adipose tissue. These substances, comprising hormones, cytokines, chemokines, and fatty acids, can be secreted by adipocytes, but also by macrophages, mast cells, or other cells within adipose tissue. In recent years, PAT has been shown to secrete a variety of adipokines (Fig. 1). The rate of excretion of various adipokines differs between PAT and other adipose tissue depots, and may vary between PAT at different sites in the vascular tree $[6 \cdot \bullet, 19 \bullet \cdot]$. Adipokines such as fatty acids, tumor necrosis factor- $\alpha$ (TNF- $\alpha)$, and adiponectin have been shown to affect insulin sensitivity, but also inflammatory responses, appetite, atherosclerosis, and hemostasis [20].

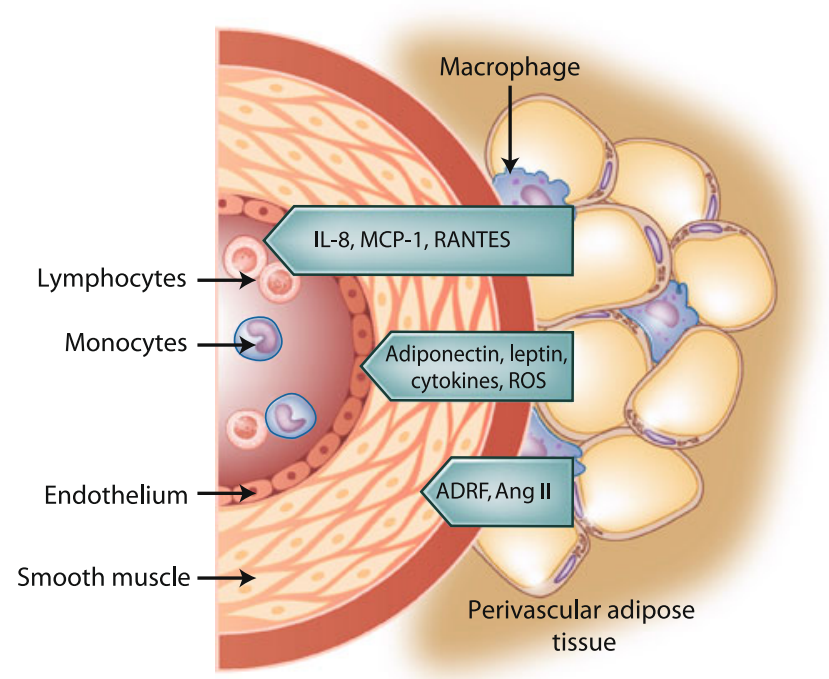

Fig. 1 Interaction of perivascular adipose tissue with vascular endothelium, smooth muscle, and immune cells and the mediators involved. $A D R F$ adventitia-derived relaxing factor; Ang II angiotensin II; IL-8 interleukin-8; $M C P-1$ monocyte chemoattractant protein 1; $R O S$ reactive oxygen species

\section{Adiponectin}

Adiponectin is an abundant protein in the human circulation that has been shown to be inversely associated with risk for type 2 diabetes, to increase insulin sensitivity, and to improve vascular function [21, 22]. Adiponectin expression is limited to adipose tissue, but paradoxically, its levels are decreased in obesity. This defect has been proposed to be caused by TNF- $\alpha$ and interleukin (IL)- 6 , as well as other inflammatory mediators [20]. Adiponectin itself can reduce production of proinflammatory cytokines, and favorably affects insulin signaling pathways [23].

Adiponectin occurs in a low molecular weight, middle molecular weight, and a high molecular weight form in the circulation, but it is not fully clear yet which form carries the highest biological activity. It has been shown that PAT in the heart [24] and in adipose tissue produces adiponectin $[6 \bullet \bullet]$. In subjects with coronary artery disease, production of adiponectin is reduced in epicardial adipose tissue [25]. The secretion of adiponectin by differentiated perivascular adipocytes, obtained from the coronaries of human organ donors, remained much lower during a 24-day course when compared with subcutaneous and perirenal adipocytes, suggesting that PAT would have a more inflammatory profile than other fat depots [19••]. Conversely, another study has reported similar concentrations of adiponectin in PAT, subcutaneous and abdominal visceral adipose tissue [26]. However, in the latter study adiponectin was measured in homogenates of the adipose depots, and synthesis does not necessarily equal secretion. 


\section{Leptin}

Leptin, the product of the ob gene discovered in 1994, is one of the best known adipokines. Deficiency of leptin activity leads to severe insulin resistance and vascular dysfunction in mice and rats [27, 28], showing that leptin controls metabolism and vascular function. Leptin has been shown to increase nitric oxide (NO) production in the presence of insulin [29]. Circulating levels of leptin are increased in obesity, but resistance to leptin's effects has been proposed to decrease leptin activity in obesity.

PAT expresses leptin, although to a somewhat lower extent than subcutaneous and perirenal adipose tissue, and leptin secretion increases during diet-induced obesity $[19 \bullet \bullet, 30]$.

\section{Cytokines and Chemokines}

A substantial number of studies have shown that PAT is a source of, predominantly proinflammatory, cytokines and chemokines [1, 9, 31], Mazurek et al. [1] found that epicardial PAT from 42 patients who underwent elective coronary artery bypass graft surgery excreted higher amounts of IL- $1 \beta$, IL-6, IL-6sR, and TNF- $\alpha$ than subcutaneous adipose tissue from these same patients. In another study, IL-6 and IL-8 excretion in differentiated perivascular adipocytes was higher than in subcutaneous and perirenal fat, as well as monocyte chemoattractant protein 1 (MCP-1) release [19••]. Importantly, the amount of cytokines excreted by PAT did not correlate with plasma cytokine concentrations. These findings illustrate the importance of adipose tissue location and that systemic concentrations of adipokines may not be representative of local concentrations in tissues. Also, the inflammatory properties of epicardial adipose tissue were independent of obesity [1].

Aside from cytokines, PAT is also a source of chemokines such as IL-8, MCP-1, and RANTES [31, 32]. These have been implicated in the initiation of vessel wall inflammation and concomitant production of cytokines.

\section{Adventitia-derived Relaxing Factor}

PAT surrounding the aorta and mesenteric arteries of rats $[3,33]$ has been shown to exert a direct relaxing effect on vascular smooth muscle, mediated by one or more adventitia-derived relaxing factors (ADRFs). One of these ADRFs has been identified as angiotensin 1-7 [34]. It is not known yet whether ADRFs are expressed by human PAT.

\section{Renin-Angiotensin System}

PAT has been shown to express all components of the renin-angiotensin system except renin [35], and has been implicated in the pathogenesis of hypertension. Interestingly, angiotensin production by mesenteric adipose tissue was found to be higher than that in periaortic adipose tissue, showing regional differences in this system [35].

\section{Reactive Oxygen Species}

Production of reactive oxygen species by PAT has primarily been found in the larger arteries of rats and mice. Reactive oxygen species production in PAT is produced by NADPH oxidase in immune cells $[32,36]$, can be increased by angiotensin [32], and has been found to be increased in experimental obesity [36].

\section{Vasoactive Properties of PAT}

Accumulating evidence suggests that the products of PAT contribute to regulation of vascular function. Moreover, vascular function, specifically microvascular functions such as tissue perfusion, contributes to the regulation of insulin sensitivity [37]. Here, we will discuss the effect of PAT on vascular function.

No data have been published directly linking insulininduced vasoreactivity, a contributor to insulin-mediated glucose uptake, to the phenotypical characteristics of PAT. It has nevertheless been hypothesized that PAT does influence insulin-induced vasoreactivity [4]. Moreover, there are numerous studies that report on the important role PAT has in vascular tone regulation. The vasoactive properties of PAT have been studied in the aorta and other large vessels, but also in the microcirculation [6••].

\section{PAT and Endothelium-dependent Vasodilation}

Endothelium is an important modifier of vascular tone and recent evidence suggests PAT alters the balance between endothelium-dependent vasodilator and vasoconstrictor substances such as NO and endothelin-1 [38]. PAT could modify vascular reactivity by secreting adipokines, some of which are known to have an effect on vasoreactivity [39]. Because the profile of adipokines secreted by PAT alters during adiposity, vascular reactivity may be altered as a consequence [19••]. The amount of PAT surrounding the brachial artery is negatively associated with post-ischemic increase in forearm blood flow, a measure of microvascular dilation downstream, but not with vasodilation at the 
brachial artery, suggesting that PAT mainly has an effect on the microcirculation through a vasocrine mechanism, or that PAT quantity around the brachial artery is associated with the amount of PAT in the microcirculation [12••]. Vascular dilation by glyceryl trinitrate administration also was not affected, precluding a direct effect of PAT on smooth muscle in this study [12••]. The observation that PAT does not have a local effect on local endothelial function is contested by evidence from ex vivo studies. In human internal thoracic arteries (ITAs), PAT has anticontractile properties in the vasoconstrictor response to $U$ 46619 (a thromboxane $\mathrm{A}_{2}$ /prostaglandin $\mathrm{H}_{2}$ receptor agonist), the concentration at which $50 \%$ of maximum constriction is achieved is the same for the ITAs with and without PAT, indicating that PAT attenuates maximum contractility, but not sensitivity to U 46619 of the endothelial cell. Endothelium-independent vasodilation was not modified by PAT in this study [40]. Anticontractile properties of PAT are not only seen in large arteries, but also in the microcirculation $[6 \bullet \bullet]$.

PAT around microvessels derived from subcutaneous gluteal fat of healthy lean subjects also possesses anticontractile properties $[6 \bullet \bullet$. When a microvessel is exposed to PAT-conditioned medium, it responds with relaxation, even in the absence of an exogenous agonist. These anticontractile properties are abrogated when a microvessel with PAT is used from patients with metabolic syndrome, suggesting functional differences between PAT from lean subjects and subjects with metabolic syndrome. Moreover, in response to norepinephrine, microvessels with PAT from lean healthy subjects exhibit less vasoconstriction than microvessels without PAT or PAT from patients with metabolic syndrome. In a further set of experiments, the anticontractile effects of PAT were abolished by scavenging adiponectin with a soluble adiponectin-receptor 1 fragment. These results point to a crucial role of adiponectin, an antiinflammatory adipokine. Also, hypoxic conditions, which are known to decrease adiponectin production, attenuate the anticontractile properties of PAT $[6 \bullet \bullet, 41]$. When microvessels with PAT from lean subjects are incubated with TNF- $\alpha$, which is a proinflammatory adipokine, the anticontractile effect is attenuated. However, blocking TNF- $\alpha$ with infliximab in experiments with PAT from patients with metabolic syndrome has no effect on microvascular tone. The authors speculate that in obesity, perivascular adipocytes increase in size, creating the hypoxic environment, which decreases adiponectin production. The authors acknowledge that other adipokines from the perivascular adipocytes probably have additional effects [6・•]. A drawback of this study is that even though the microvessels used are harvested from humans, the microvessels and PAT were harvested from gluteal fat biopsies. Microvessels situated in a large depot of adipose tissue may respond differently to PAT-derived adipokines than microvessels in other tissues such as muscle and heart. Moreover, these are all acute experiments and chronic exposure to the factors secreted by PAT could have different effects.

The anticontractile effects of PAT are also seen with mesenteric arteries from lean New Zealand black (NZB) mice, in which vasoconstriction in response to norepinephrine, endothelin, and angiotensin II is acutely blunted. These anticontractile properties are abolished in the New Zealand obese (NZO) mice. Conversely, PAT does not affect vasodilation in response to acetylcholine or bradykinin in either NZB or NZO mice [36].

PAT itself could be a source of NO, as PAT increases diaminofluorescein (DAF) fluorescence, a marker of NO, under stimulation of leptin after 8 weeks of a high-fat diet, preserving vascular reactivity [42]. It should be noted that nitric oxide synthase inhibitors were not used in combination with DAF in this study, and therefore DAF fluorescence may be caused by radicals other than NO. Leptin could be a stimulator of NO production, but, in contrast, epicardial PAT from swine with a diet-induced metabolic syndrome excretes more leptin than epicardial PAT in lean swine, and the increased production of leptin attenuates endothelium-dependent vasodilation [30]. Moreover, endothelial function can be restored by adding a leptin antagonist. In this study, the authors only report on leptin excretion by PAT, and not on other adipokines. Leptin concentration in the mesenteric arteries in spontaneously hypertensive rats (SHRs) is lower than in Wistar-Kyoto (WKY) rats, but leptin causes more vascular relaxation in SHRs. Leptin-induced relaxation is not modulated by PAT in both WKY and SHRs [43]. Taken together, leptin released by PAT may cause vasodilation or vasoconstriction, depending on the location of PAT.

Remarkably, hyperglycemia potentiates the anticontractile effect of periaortic PAT on the endothelium in response to phenylephrine [44]. In the presence of PAT acute hyperglycemia blunts contraction of aortic rings on phenylephrine in the presence of PAT, irrespective of the presence of endothelium. When PAT is removed from the aortic rings, acute hyperglycemia has no effect on reactivity of the aorta to phenylephrine, irrespective of the presence of endothelium.

Aortic rings with intact PAT and endothelium exhibit the least contraction in response to phenylephrine, and aortic rings stripped of both PAT and endothelium show the most contraction. Aortic rings stripped of either PAT or endothelium had intermediary responses. These results hold true for control rats as well as streptozocin (STZ) rats, a model for type 1 diabetes mellitus. Removal of PAT increases the vasoconstrictor response to phenylephrine in STZ rats more than in control rats, regardless of the presence of endothe- 
lium. The decrease in contraction to serotonin was similar in the control and STZ rats, in both the presence, as well as the absence, of endothelium [44].

Thus, PAT enhances endothelium-dependent vasodilation, probably through adiponectin or leptin. Contrarily, leptin may also enhance vascular constriction. The exact mechanisms through which PAT modulates (micro-)vascular tone remain to be investigated. Moreover, there not only seems to be an endothelium-dependent effect, but also a direct effect on smooth muscle function.

\section{Direct Effect of PAT on Smooth Muscle Tone}

Vascular tone is not only regulated by the endothelium, but the smooth muscle cells, which are responsible for vascular tone, can be directly affected by vasoactive substances as well.

In rodent models, PAT of the aorta and mesenteric bed secretes a substance called ADRF (also called PVRF [PATderived relaxing factor]) [45], which directly acts on smooth muscle cells. At present it is not fully clear if there is one or more $\mathrm{ADRF}$ and what the $\mathrm{ADRF}(\mathrm{s})$ are. The modulating effect of ADRF on vascular reactivity is mediated by potassium channels in the smooth muscle cells. Galvez et. al. [43] performed experiments on PAT in WKY rats and SHRs. In a perfused mesenteric bed, the perfusion pressure increase is greater in WKY than in SHR after potassium channel blockade with 4-aminopyridine (4-AP). The more PAT is present, the larger the response to 4-AP. The increase in perfusion pressure after potassium channel blockade indicates that PAT secretes a potassium channel-dependent anticontractile substance. Moreover, both sodium nitroprusside and acetylcholine decrease perfusion pressure in the same magnitude in the perfused mesenteric bed of WKY and SHR, which points to a smooth muscle cell effect, and not to endothelium-dependent relaxation. In isolated mesenteric arteries the vasoconstriction generated by serotonin is blunted by PAT in both WKY as well as SHR [43], which also points to smooth muscle cell dependency. The anticontractile effect of PAT is greater in WKY, so that functional changes in PAT may contribute to the higher arterial tone in SHR [43]. In lipoatrophic mice, vascular constriction on phenylephrine was aggravated in aortic rings compared with wild-type mice, due to the absence of PAT. Perfusion pressure in the mesenteric vascular bed was also increased in response to phenylephrine [46].

Serotonin increases perfusion pressure more in perfused mesenteric vascular beds of mice without PAT than in perfused mesenteric vascular beds in the presence of PAT. In adiponectin knockout mice PAT retained anticontractile properties, thereby suggesting that adiponectin is not ADRF [26]. However, when in experiments with human arteries, adiponectin action is blocked through an adiponectin type 1 receptor fragment, the anticontractile properties of PAT are completely attenuated [6••]. One of the ADRFs recently identified is angiotensin 1-7, which activates the Mas receptor, resulting in vasorelaxation [34]. Whether angiotensin 1-7, or another ADRF, is secreted by human PAT, and what its role is in vasoreactivity remains to be proven.

Thus, PAT has anticontractile properties, and some but not all studies find that this effect is mediated by the endothelium. Data on the functional change of PAT in adiposity are not conclusive, but most studies find that the anticontractile properties are lost in obesity.

\section{PAT and Insulin Sensitivity}

As mentioned above, vascular function and especially microvascular blood volume in muscle are related to insulin sensitivity. Because obesity is associated with insulin resistance, reduction of microvascular blood volume, and altered properties of PAT, we have proposed that PAT causes microvascular dysfunction and insulin resistance in obesity [4]. Although there are, at present, no studies that prospectively link PAT to diabetes, a number of studies provide indirect evidence for this hypothesis.

First, several studies suggest that ectopic adipose tissue, especially within muscles, strongly relates to insulin sensitivity. The amount of PAT surrounding the brachial artery [12••] and adipose tissue between muscle (intermuscular adipose tissue [IMAT]) [47] are inversely related to insulin sensitivity. Even though IMAT accounts for only 3\% of total thigh adipose tissue, it has the strongest correlation with insulin sensitivity in obese subjects and subjects with type 2 diabetes mellitus. After a 16-week weight loss program, the IMAT compartment in the thigh decreased stronger than subcutaneous fat and subfascial fat [48].

Second, vascular function, especially muscle perfusion, contributes to regulation of insulin-mediated glucose disposal. Increased amounts of adipose tissue, as observed in obese subjects and rats, are accompanied by impairment of muscle perfusion. Impairment of muscle perfusion has been estimated to account for $30 \%$ to $50 \%$ of insulin resistance [49].

Third, we have found accumulation of PAT around the arterioles that regulate muscle perfusion. Aside from intermuscular adipose tissue and PAT around the femoral artery, we have found that PAT exists within muscles (ie, intramuscular PAT [mPAT]) [unpublished data]. This location is especially relevant given the increasing evidence for regulation of muscle insulin sensitivity by microvascular perfusion in muscle [49, 50]. By regulating endotheliumdependent vasodilatation, insulin-mediated vasoreactivity, and muscle perfusion, mPAT may control muscle glucose uptake and, thus, determine risk of future type 2 diabetes. 
Using selective manipulation of PAT, this hypothesis remains to be tested in future studies.

Taken together, these data support the hypothesis that PAT is involved in the development of insulin resistance. The strongest data for or against this hypothesis will likely come from PAT-specific transgenic mouse models, but at present such models do not exist.

\section{Conclusions}

PAT is increasingly recognized as a widespread, relevant tissue in vascular biology and important determinant of cardiovascular complications of obesity. Recent studies have shown that PAT relates to endothelium-dependent vasodilatation and inflammation by secreting a variety of substances that affect vascular tone and infiltration of inflammatory cells. The mechanisms controlling the quantity of PAT and adipokine secretion from PAT remain to be determined. Because PAT is related to insulin resistance, controls vascular function, and is located within insulin target tissues, it may well contribute to the pathogenesis of type 2 diabetes as well as cardiovascular disease.

Acknowledgements Etto C. Eringa, Rick I. Meijer, Yvo M. Smulders and Erik H. Serne are supported by the Netherlands Heart Foundation (NHF). Etto C. Eringa is supported by the Netherlands Organisation for Scientific Research. Victor W.M. van Hinsbergh is supported by the Netherlands Initiative for Regenerative Medicine (NIRM).

Disclosure No potential conflicts of interest relevant to this article were reported. This review is supported by a grant from The Netherlands Heart Foundation (grant 2009B098).

Open Access This article is distributed under the terms of the Creative Commons Attribution Noncommercial License which permits any noncommercial use, distribution, and reproduction in any medium, provided the original author(s) and source are credited.

\section{References}

Papers of particular interest, published recently, have been highlighted as:

•- Of major importance

1. Mazurek T, Zhang L, Zalewski A, Mannion JD, Diehl JT, Arafat H, et al. Human epicardial adipose tissue is a source of inflammatory mediators. Circulation. 2003;108(20):2460-6.

2. Police SB, Thatcher SE, Charnigo R, Daugherty A, Cassis LA. Obesity promotes inflammation in periaortic adipose tissue and angiotensin II-induced abdominal aortic aneurysm formation. Arterioscler Thromb Vasc Biol. 2009;29(10):1458-64.

3. Verlohren S, Dubrovska G, Tsang SY, Essin K, Luft FC, Huang Y, et al. Visceral periadventitial adipose tissue regulates arterial tone of mesenteric arteries. Hypertension. 2004;44(3):271-6.
4. Yudkin JS, Eringa E, Stehouwer CD. "Vasocrine" signalling from perivascular fat: a mechanism linking insulin resistance to vascular disease. Lancet. 2005;365(9473):1817-20.

5. Montani JP, Carroll JF, Dwyer TM, Antic V, Yang Z, Dulloo AG. Ectopic fat storage in heart, blood vessels and kidneys in the pathogenesis of cardiovascular diseases. Int J Obes Relat Metab Disord. 2004;28 Suppl 4:S58-65.

6. •- Greenstein AS, Khavandi K, Withers SB, Sonoyama K, Clancy O, Jeziorska $\mathrm{M}$, et al. Local inflammation and hypoxia abolish the protective anticontractile properties of perivascular fat in obese patients. Circulation. 2009;119(12):1661-70. In this article, it is shown for the first time that adiponectin from human PAT surrounding resistance arteries increases NO bioavailability. In subjects with metabolic syndrome, this effect on vasodilation is blunted.

7. Hu Y, Zhang Z, Torsney E, Afzal AR, Davison F, Metzler B, et al. Abundant progenitor cells in the adventitia contribute to atherosclerosis of vein grafts in ApoE-deficient mice. J Clin Invest. 2004;113(9):1258-65.

8. Thureson-Klein A, Stijarne L. Ultrastructural features of mast cells in human omental veins. Blood Vessels. 1979;16(6):311-9.

9. Takaoka M, Suzuki H, Shioda S, Sekikawa K, Saito Y, Nagai R, et al. Endovascular injury induces rapid phenotypic changes in perivascular adipose tissue. Arterioscler Thromb Vasc Biol. 2010;30(8):1576-82.

10. Tang W, Zeve D, Suh JM, Bosnakovski D, Kyba M, Hammer RE, et al. White fat progenitor cells reside in the adipose vasculature. Science. 2008;322(5901):583-6.

11. Iacobellis G, Ribaudo MC, Assael F, Vecci E, Tiberti C, Zappaterreno A, et al. Echocardiographic epicardial adipose tissue is related to anthropometric and clinical parameters of metabolic syndrome: a new indicator of cardiovascular risk. J Clin Endocrinol Metab. 2003;88(11):5163-8.

12. •• Rittig K, Staib K, Machann J, Bottcher M, Peter A, Schick F, et al. Perivascular fatty tissue at the brachial artery is linked to insulin resistance but not to local endothelial dysfunction. Diabetologia 2008;51(11):2093-9. This article shows that the amount of PAT around the brachial artery correlates with wholebody insulin sensitivity; this correlation is independent from the amount of visceral adipose tissue.

13. De Coppi P, Milan G, Scarda A, Boldrin L, Centobene C, Piccoli $\mathrm{M}$, et al. Rosiglitazone modifies the adipogenic potential of human muscle satellite cells. Diabetologia. 2006;49(8):1962-73.

14. Moon YS, Smas CM, Lee K, Villena JA, Kim KH, Yun EJ, et al. Mice lacking paternally expressed Pref-1/Dlk1 display growth retardation and accelerated adiposity. Mol Cell Biol. 2002;22 (15):5585-92.

15. Liu J, Divoux A, Sun J, Zhang J, Clement K, Glickman JN, et al. Genetic deficiency and pharmacological stabilization of mast cells reduce diet-induced obesity and diabetes in mice. Nat Med. 2009;15(8):940-5.

16. Ito S, Narumiya S, Hayaishi O. Prostaglandin D2: a biochemical perspective. Prostaglandins Leukot Essent Fatty Acids. 1989;37 (4):219-34.

17. Feldon SE, O'Loughlin CW, Ray DM, Landskroner-Eiger S, Seweryniak KE, Phipps RP. Activated human T lymphocytes express cyclooxygenase- 2 and produce proadipogenic prostaglandins that drive human orbital fibroblast differentiation to adipocytes. Am J Pathol. 2006;169(4):1183-93.

18. Tsuruda T, Kato J, Hatakeyama K, Kojima K, Yano M, Yano Y, et al. Adventitial mast cells contribute to pathogenesis in the progression of abdominal aortic aneurysm. Circ Res. 2008;102(11):1368-77.

19. •• Chatterjee TK, Stoll LL, Denning GM, Harrelson A, Blomkalns AL, Idelman G, et al. Proinflammatory phenotype of perivascular adipocytes: influence of high-fat feeding. Circ Res 2009;104(4):5419. The authors show that PAT exhibits an increased proinflamma- 
tory response after 2 weeks of high-fat diet; this response is stronger in PAT than in other adipose tissue depots. Therefore, PAT can be considered a distinctive depot of adipose tissue.

20. Tilg H, Moschen AR. Adipocytokines: mediators linking adipose tissue, inflammation and immunity. Nat Rev Immunol. 2006;6 (10):772-83.

21. Koenig W, Khuseyinova N, Baumert J, Meisinger C, Lowel H. Serum concentrations of adiponectin and risk of type 2 diabetes mellitus and coronary heart disease in apparently healthy middle-aged men: results from the 18-year follow-up of a large cohort from southern Germany. J Am Coll Cardiol. 2006;48 (7):1369-77.

22. Duncan BB, Schmidt MI, Pankow JS, Bang H, Couper D, Ballantyne CM, et al. Adiponectin and the development of type 2 diabetes: the atherosclerosis risk in communities study. Diabetes. 2004;53(9):2473-8.

23. Luo N, Liu J, Chung BH, Yang Q, Klein RL, Garvey WT, et al. Macrophage adiponectin expression improves insulin sensitivity and protects against inflammation and atherosclerosis. Diabetes. 2010;59(4):791-9.

24. Date H, Imamura T, Ideguchi T, Kawagoe J, Sumi T, Masuyama $\mathrm{H}$, et al. Adiponectin produced in coronary circulation regulates coronary flow reserve in nondiabetic patients with angiographically normal coronary arteries. Clin Cardiol. 2006;29(5):211-4.

25. Iacobellis G, Pistilli D, Gucciardo M, Leonetti F, Miraldi F, Brancaccio G, et al. Adiponectin expression in human epicardial adipose tissue in vivo is lower in patients with coronary artery disease. Cytokine. 2005;29(6):251-5.

26. Fesus G, Dubrovska G, Gorzelniak K, Kluge R, Huang Y, Luft $\mathrm{FC}$, et al. Adiponectin is a novel humoral vasodilator. Cardiovasc Res. 2007;75(4):719-27.

27. Zhang Y, Proenca R, Maffei M, Barone M, Leopold L, Friedman JM. Positional cloning of the mouse obese gene and its human homologue. Nature. 1994;372(6505):425-32.

28. Wallis MG, Wheatley CM, Rattigan S, Barrett EJ, Clark ADH, Clark MG. Insulin-mediated hemodynamic changes are impaired in muscle of zucker obese rats. Diabetes. 2002;51(12):3492-8.

29. Vecchione C, Aretini A, Maffei A, Marino G, Selvetella G, Poulet $\mathrm{R}$, et al. Cooperation between insulin and leptin in the modulation of vascular tone. Hypertension. 2003;42(2):166-70.

30. Payne GA, Borbouse L, Kumar S, Neeb Z, Alloosh M, Sturek M, et al. Epicardial perivascular adipose-derived leptin exacerbates coronary endothelial dysfunction in metabolic syndrome via a protein kinase C-beta pathway. Arterioscler Thromb Vasc Biol. 2010;30(9):1711-7.

31. Henrichot E, Juge-Aubry CE, Pernin A, Pache JC, Velebit V, Dayer JM, et al. Production of chemokines by perivascular adipose tissue: a role in the pathogenesis of atherosclerosis? Arterioscler Thromb Vasc Biol. 2005;25(12):2594-9.

32. Guzik TJ, Hoch NE, Brown KA, McCann LA, Rahman A, Dikalov S, et al. Role of the T cell in the genesis of angiotensin IIinduced hypertension and vascular dysfunction. J Exp Med. 2007;204(10):2449-60.

33. Dubrovska G, Verlohren S, Luft FC, Gollasch M. Mechanisms of ADRF release from rat aortic adventitial adipose tissue. Am J Physiol Heart Circ Physiol. 2004;286(3):H1107-13.

34. Lee RM, Lu C, Su LY, Gao YJ. Endothelium-dependent relaxation factor released by perivascular adipose tissue. J Hypertens. 2009;27(4):782-90.

35. Galvez-Prieto B, Bolbrinker J, Stucchi P, de las Heras AI, Merino $\mathrm{B}$, Arribas $\mathrm{S}$, et al. Comparative expression analysis of the renin- angiotensin system components between white and brown perivascular adipose tissue. J Endocrinol. 2008;197(1):55-64.

36. Marchesi C, Ebrahimian T, Angulo O, Paradis P, Schiffrin EL. Endothelial nitric oxide synthase uncoupling and perivascular adipose oxidative stress and inflammation contribute to vascular dysfunction in a rodent model of metabolic syndrome. Hypertension. 2009;54(6):1384-92.

37. Clark MG. Impaired microvascular perfusion: a consequence of vascular dysfunction and a potential cause of insulin resistance in muscle. Am J Physiol Endocrinol Metab. 2008;295(4): E732-50.

38. Bakker W, Eringa EC, Sipkema P, van Hinsberg VW. Endothelial dysfunction and diabetes: roles of hyperglycemia, impaired insulin signaling and obesity. Cell Tissue Res. 2009;335(1):165-89.

39. Eringa EC, Stehouwer CD, Walburg K, Clark AD, van Nieuw Amerongen GP, Westerhof N, et al. Physiological concentrations of insulin induce endothelin-dependent vasoconstriction of skeletal muscle resistance arteries in the presence of tumor necrosis factor-alpha dependence on c-Jun N-terminal kinase. Arterioscler Thromb Vasc Biol. 2006;26(2):274-80.

40. Gao YJ, Zeng ZH, Teoh K, Sharma AM, Abouzahr L, Cybulsky I, et al. Perivascular adipose tissue modulates vascular function in the human internal thoracic artery. J Thorac Cardiovasc Surg. 2005;130(4):1130-6.

41. Chen B, Lam KS, Wang Y, Wu D, Lam MC, Shen J, et al. Hypoxia dysregulates the production of adiponectin and plasminogen activator inhibitor-1 independent of reactive oxygen species in adipocytes. Biochem Biophys Res Commun. 2006;341(2):549-56.

42. Gil-Ortega M, Stucchi P, Guzman-Ruiz R, Cano V, Arribas S, Gonzalez MC, et al. Adaptative nitric oxide overproduction in perivascular adipose tissue during early diet-induced obesity. Endocrinology. 2010;151(7):3299-306.

43. Galvez B, de Castro J, Herold D, Dubrovska G, Arribas S, Gonzalez MC, et al. Perivascular adipose tissue and mesenteric vascular function in spontaneously hypertensive rats. Arterioscler Thromb Vasc Biol. 2006;26(6):1297-302.

44. Lee RM, Lu C, Su LY, Werstuck G, Gao YJ. Effects of hyperglycemia on the modulation of vascular function by perivascular adipose tissue. J Hypertens. 2009;27(1):118-31.

45. Gao YJ, Lu C, Su LY, Sharma AM, Lee RM. Modulation of vascular function by perivascular adipose tissue: the role of endothelium and hydrogen peroxide. Br J Pharmacol. 2007;151 (3):323-31.

46. Takemori K, Gao YJ, Ding L, Lu C, Su LY, An WS, et al. Elevated blood pressure in transgenic lipoatrophic mice and altered vascular function. Hypertension. 2007;49(2):365-72.

47. Boettcher M, Machann J, Stefan N, Thamer C, Haring HU, Claussen $\mathrm{CD}$, et al. Intermuscular adipose tissue (IMAT): association with other adipose tissue compartments and insulin sensitivity. J Magn Reson Imaging. 2009;29(6):1340-5.

48. Goodpaster BH, Thaete FL, Kelley DE. Thigh adipose tissue distribution is associated with insulin resistance in obesity and in type 2 diabetes mellitus. Am J Clin Nutr. 2000;71(4):885-92.

49. Barrett EJ, Eggleston EM, Inyard AC, Wang H, Li G, Chai W, et al. The vascular actions of insulin control its delivery to muscle and regulate the rate-limiting step in skeletal muscle insulin action. Diabetologia. 2009;52(5):752-64.

50. Eringa EC, Bakker W, Smulders YM, Serne EH, Yudkin JS, Stehouwer CD. Regulation of vascular function and insulin sensitivity by adipose tissue: focus on perivascular adipose tissue. Microcirculation. 2007;14(4-5):389-402. 